\title{
Wavelets Analysis of the Baltic Equity Market: Risk and Co-Movement with the European Market
}

\section{Arvydas Kregzde}

\author{
Vilnius University \\ Naugarduko 24, Vilnius, Lithuania \\ E-mail.arvydas.kregzde@mif.vu.lt
}

cross $^{\text {ref }}$ http://dx.doi.org/10.5755/j01.ee.29.5.19330

\begin{abstract}
This paper's objective is to explore equity market risk and co-movements between the Baltic stock markets of Estonia, Latvia and Lithuania and the European stock markets both in time and frequency dimensions. We analyse equity markets returns risk across different time horizons (frequencies). At the same time, we focus on the changes of the market risk and comovements of the Baltic and the European markets returns in time. The aim of the paper is to find the frequencies and time when volatility and co-movements change. We use monthly data in the period of 2000-2017. The wavelet analysis was employed to segregate the risk and co-movements at different time and different frequencies. Compared to previous studies, a novelty of the paper is the investigation of the markets at each time horizon separately. Our findings are consistent with the findings of other researchers who indicated that the Baltic markets are more integrated with the developed European stock markets during crisis periods. We have found some impact of accession to the EU on co-movements between the Baltic equity markets and the European market. We have discovered that co-movements are greater in low frequencies. From the investment diversification point of view, the effect depends on the investment horizon. Our conclusion is that for the investor with a time horizon of over 1.5 years diversification with the Baltic markets is not very efficient.
\end{abstract}

Keywords: Baltic; European; Wavelets; Co-Movement; Equity; Volatility; Risk.

\section{Introduction}

Financial institutions have various objectives for their investments and the horizon of the investments reflects the goals of the institution. For the fund manager it is crucial to distinguish the short-term and the long-term decisions. Consequently, the risk manager has to evaluate the shortterm and the long-term risks. The first kind of the risk is related to the higher frequencies that is the short-term fluctuation of the market, where the latter depends on the lower frequencies, that is the long-term fluctuations. Different duration of the investments requires analysis of the risk across various frequencies.

The portfolio manager pays high attention to the diversification of the portfolio. The benefit of the diversification depends on co-movements of the asset in the portfolio. The interrelation of the assets is changing over time and is different at particular frequencies. Therefore, the risk manager must take into account the changing environment in the sense of time and frequency.

The wavelet transformation analysis enables us to measure the changes of the risk and co-movement of the assets over time and allows finding changes of the risk and comovements at different frequencies. Therefore, according to Dewandaru et al. (2015), wavelet analysis is a proper tool to investigate heterogeneity of the financial series. Chakrabarty et al. (2015)) noticed that wavelet based multi-scale analysis of financial time series has attracted much attention, from both the academia and practitioners from all around the world.

The scientific papers analysing the Baltic stock market are based mostly on the classical econometric approach. Nekhili et al. (2002) stressed that widely used parametric models like the random walk with GARCH, random walk with stochastic volatility, jump diffusion processes etc. have been found insufficient in explicating the underlying dynamics of the financial market across all frequency levels.

The purpose of the paper is to analyse the Baltic equity markets returns risk across all frequencies. At the same time, we focus on the changes of the market risk and comovements of the Baltic and the European markets returns in time. For this purpose, we decompose the time series into the frequency-time dimensions using continuous wavelet transformation. The wavelet power spectrum allows us to find the time of the highest and the lowest volatility of the market and to describe the time horizons, for which the risk is high or low. We use cross-wavelet spectrum and wavelet coherence to measure co-movements of the Baltic and the European markets returns. It enables us to discover the time when risk changes and to find the frequencies at which the risk and co-movements are concentrated.

\section{Theoretical Background}

A number of authors have analysed the Baltic stock markets from a co-movement point of view. Deltuvaite (2016) studied an interrelation between the stock markets in the Baltic states. By using the Spearman's correlation coefficient and the Granger causality test she found that all the three Baltic stock markets were closely related, yet the Latvian stock market was more isolated at the regional level, compared to the other two Baltic stock markets, whereas the Estonian and the Lithuanian stock markets were more interrelated. Nikkinen et al. (2012) investigated linkages between the Nordic, the Baltic and the major global stock markets, with a particular focus on the period of the financial crisis of 2008-2009. The results of the study indicated that 
the Baltic stock markets became closely related to the main European stock markets during and after the crisis. Babalos at el. (2018) explored stock market integration between the developed European markets of Germany, France and UK and the emerging Baltic stock markets of Estonia, Latvia and Lithuania during the period of 2001-2014. They found the integration to be significantly increased after the crisis. Syllignakis and Kouretas (2011) applied the Dynamic Conditional Correlation (DCC) multivariate GARCH model of Engle (2002) to examine time-varying conditional correlations to the weekly index returns. They discovered that there was a statistically significant increase in conditional correlations between the US and the German stock returns and the CEE stock returns, particularly during the financial crises of 2007-2009. Alexakis et al. (2016) investigated the contagion effect of the Baltic market during the crisis. Co-movement and volatility transmission between the oil price and stock markets in the Baltic states was investigated by Bein (2017). Alekneviciene et al. (2012) went inside the Lithuanian stock market to investigate a portfolio of different weight stocks and compared a diversification effect of differently-weighted stocks portfolios. Kregzde and Murauskas (2015) revealed the relationship between the Lithuanian Credit Default Swaps and the bond market, by using Vector Error Correction model. Maneschiold (2006) examined the short-run and the long-run dynamics between the Baltic and international capital markets. By applying the Johansen co-integration method, the author showed that the Baltic capital markets were not strongly integrated with international markets, thus indicating a good area of investment for international investors seeking to diversify their portfolio. Noteworthy, the author's conclusion had been made before the financial crisis in 2008. Our paper confirms the findings of other authors, yet it also expands understanding of the markets in the way that goes inside the co-movements (co-movements in each frequency).

Risk management is the key issue for investors and it constantly attracts a high attention of scientists. Several econometric models were used to estimate the risk and the level and co-movements of the stock market return: Vector Autoregressive (VAR) models (Gilmorea \& McManus, 2002), GARCH models (Egert \& Kocenada, 2010)), etc. The level of co-movement has a direct practical application in making decisions concerning asset allocation and risk management. The increased co-movement of stock market returns may reduce the advantages of international diversification of investments (Ling \& Dhesi, 2010). One of the concepts most commonly used for measuring of comovement of financial markets is the correlation coefficient of time series of the returns. The studies (see for example Lin et al. (1994), Forbes and Rigobon (2002), Brooks and Del Negro $(2005,2006)$ ) have revealed that co-movement of markets is not constant over time. To estimate co-movement for different time periods a rolling window correlation coefficient or non-overlapping sample periods were applied (King \& Wadhawani, 1990; Lin et al., 1994).

In addition to the time variation of risk and comovements, a distinction between the short-term and the long-term goals (see Candelon et al. (2008)) should be taken into account. Volatility and co-movements of the markets are not constant across the frequencies (see for example
Banulescu-Radu et al. (2016)). We define the frequency bands below 1 year as higher frequency bands and the frequency bands above 1 year as lower frequency bands (see Dewandaru et al. (2015)). We treat long-term and short-term investors as defined by Calderon et al. (2008) and Rua and Nunes (2012). The short-term investors are more interested in risk assessment at higher frequencies, i.e. short-term fluctuations, whereas long-term investors focus on a risk at lower frequencies, i.e. long-term fluctuations. According to Chakrabarty et al. (2015), "Short-term fluctuations are induced by short-term traders (like day traders, intra-day traders and hedge funds) who rely on idiosyncratic (firm specific) news more than on systematic (market specific) news. Hence their trading activities are un-correlated with the common market dynamics. Long-term traders (like central Government and pension funds), on the other hand, rely more on systematic (market and economy specific) news and hence their trading activities are more correlated with the market movements". Analysis at the frequency level provides a valuable source of information, considering that different financial decisions occur at different frequencies. Hence, one has to resort to the frequency domain analysis to obtain insights about the co-movement at the frequency level (see, for example, Woitek (2001) and Pakko (2004)).

In this paper we analyse the risk of the Baltic stock market and co-movements between the Baltic stock markets and the European stock market in both time and frequency domains. We use wavelet analysis to explore co-movements of equity markets in the Baltic states. Starting with the studies of Ramsey and Zhang $(1996,1997)$ and Ramsey and Lampart (1998), a number of research in economics and finance was carried out based on wavelet analysis. Kim and In (2003, 2005) and Babalos et al. (2016) investigated the relationship between financial variables and the real economic activity. Gallegati (2008) and Yogo (2008) applied wavelets for business cycle analysis, and Gallegati et al. (2014) analysed interest rate spreads and output. Rua (2012) analysed monetary policy issues in the euro area. A number of papers have been devoted to application of wavelets to reveal co-movements of equity markets. Rua and Nunes (2009) investigated international co-movement of stock market returns by means of wavelet analysis. Dajcman (2012) studied dynamics of returns co-movement in the Czech and the European stock markets during the period of 1997-2010. Barunik and Vacha (2013) analysed the contagion among the Central and the Eastern European stock markets during the financial crisis in a very high frequency. Polanco-Martinez et al. (2018) studied peripheral EU stock markets by means of wavelet transform.

Compared to the previous studies, a novelty of the paper is the use, for the first time, of wavelet analysis for investigation of the Baltic markets. The previous analyses of the Baltic markets were made by applying a classical econometrical approach. Wavelet analysis allows decomposing of the time series of returns into time and frequency dimensions. The decomposition creates opportunities to compare different markets not only in time, but also in frequency. Higher comovements during the crisis have been observed by other authors as well. We have gone deeper and discovered, for the first time, the time horizons in which the co-movements are concentrated. We have established that the co-movements appear in lower frequencies. 


\section{Methodology}

We apply wavelet transform analysis for the time series of returns. The wavelet transform analysis uses little wavelike functions known as wavelets. A family of wavelets $\psi_{\tau, s}(t)$ is defined by using the basic wavelet functions $\psi(t)$, called a mother wavelet, in the following way:

$$
\psi_{\tau, s}(t)=\frac{1}{\sqrt{s}} \psi\left(\frac{t-\tau}{s}\right)
$$

There variable $s$ (dilation parameter) is the scale and $\tau$ (translation parameter) is the time. The scale $s$ is proportional to the inverse of the frequency.

The continuous wavelet transformation (CWT) of a time series $\mathrm{x}(\mathrm{t})$ is defined trough the following formula:

$$
W_{x}(\tau, s)=\int_{-\infty}^{\infty} x(t) \psi_{\tau, s}^{*}(t) d t
$$

there $\psi^{*}$ denotes the complex conjugate of $\psi$. We face discreet time series $x(t)$, therefore for $t=1, \ldots N$ CWT is calculated as follows:

$$
W_{x}(\tau, s)=\sum_{t=1}^{N} x(t) \psi_{\tau, s}^{*}(t)
$$

The CWT is used to transform the initial time series $\mathrm{x}(\mathrm{t})$ into another representation, separating time $\tau$ and scale (frequency) $s$.

Wavelet power spectrum (WPS) for each $\mathrm{s}$ and $\tau$ is defined as follows:

$$
\operatorname{WPS}(\tau, s)=\left|W_{x}(\tau, s)\right|^{2}
$$

It measures the time series variance at each time and at each scale with respect to the wavelet $\psi$. A plot of WPS is called a scalogram. One can define the average of WPS across the time for each scale s. It is known as global wavelet power spectrum GPWS (see Tiwari at el. (2017)), or energy distribution at a specific scale (see Addison (2016)).

$$
E(s)=\frac{1}{N} \sum_{\tau=1}^{N}\left|W_{x}(\tau, s)\right|^{2}
$$

$E(s)$ measures average variance at the frequency corresponding to scale s. Peaks in $E(s)$ highlights the dominant scales within the time series $\mathrm{x}(\mathrm{t})$.

Cross-wavelet spectrum of two time series $\mathrm{x}(\mathrm{t})$ and $\mathrm{y}(\mathrm{t})$ with wavelet transforms $W_{x}(\tau, s)$ and $W_{y}(\tau, s)$ is defined as $W_{x y}(\tau, s)=W_{x}(\tau, s) W_{y}^{*}(\tau, s)$. It captures the covariance between two time series in the time-frequency space.

We define the wavelet transformation coherence (WTC) or simply coherency of two time series $\mathrm{x}(\mathrm{t})$ and $\mathrm{y}(\mathrm{t})$ in the way as it is described by Torrence and Compo (1998) by the following formula:

$$
R^{2}(\tau, s)=\frac{\left|\mathrm{s}\left(s^{-1} W_{x y}(\tau, s)\right)\right|^{2}}{\mathrm{~S}\left(s^{-1}\left|W_{x}(\tau, s)\right|^{2}\right) \mathrm{S}\left(s^{-1}\left|W_{y}(\tau, s)\right|^{2}\right)}
$$

There $\mathrm{S}(\bullet)$ is a smoothed (see Torrence and Compo (1998)) operator and $s$ is the wavelet scale. It allows us to estimate the presence of the simple cause-effect relationship between the phenomena recorded in the time series. The coherency is the analogy of the correlation coefficient. One can define the average coherency across time at each scale for discreet series of time $\tau$ as follows:

$$
A C(s)=\frac{1}{N} \sum_{\tau=1}^{N} R^{2}(\tau, s)
$$

We use a complex Morlet as a mother wavelet which is defined as follows:

$$
\psi(t)=\pi^{-\frac{1}{4}} e^{i \omega_{0} t} e^{-\frac{t^{2}}{2}}
$$

In this way the Morlet wavelet mother function consists of the multiplier $e^{i \omega_{0} t}=\cos \left(\omega_{0} t\right)+i \sin \left(\omega_{0} t\right)$ which is a periodic function with a period of $\frac{2 \pi}{\omega_{0}}$ and the Gausian envelope $e^{-\frac{t^{2}}{2}}$ which tends to zero as $t \rightarrow \pm \infty$. We fix $\omega_{0}=6$, because it provides for a good balance of time and frequency (see Grinsted et al. (2004)).

\section{Research Findings}

\section{Data}

We use OMX Riga (Latvia), OMX Tallinn (Estonia) and OMX Vilnius (Lithuania) as indices representing the Baltic stock markets and Dow Jones Euro Stoxx 50 (Eurostoxx50) to represent the European market. Eurostoxx50 data comes from the ECB Data Warehouse. Data of OMX Riga, OMX Tallinn and OMX Vilnius have been imported from the OMX Nasdaq website. The data sample ranges from January 2000 to February 2017. We have chosen January 2000 as a starting point due to the introduction of the uniform methodise for the Baltic stock indices market. In total, our time series consist of 205 monthly data points.

To make the value of each index in January 2000 to be equal to 1 we have multiplied values of each index by the normalised factor. The indices under consideration are presented in Figure1.

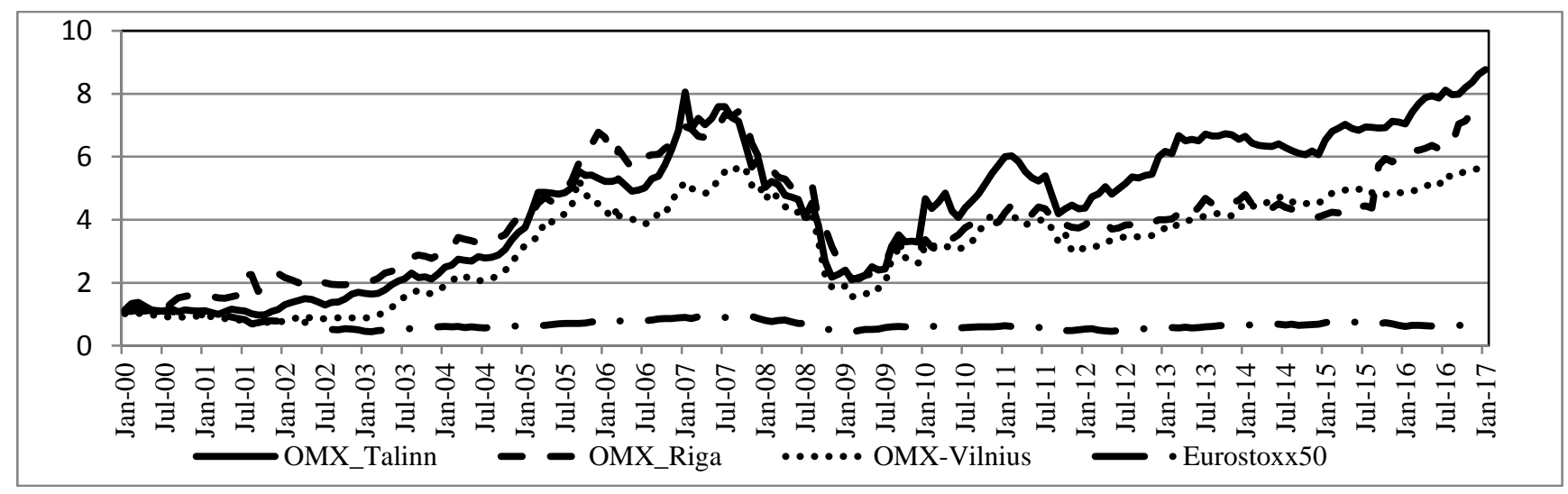

Figure 1. Values of the normalised indices of Eurostoxx 50, OMX Tallinn, OMX Riga and OMX Vilnius. Source: performed by the author. 
Returns of stock indices are calculated as the logarithmic of the ratio of the closing prices at the beginning of the current month and at the beginning of the previous month. Descriptive statistics of the returns are presented in
Table 1. During the period of 17 years, the average of monthly returns of the Baltic states exceeded $0.8 \%$ and the average of monthly returns of the Eurozone was negative and equal to $-0.2 \%$.

Descriptive Statistics of Monthly Returns of Stock Indices

\begin{tabular}{|c|c|c|c|c|c|c|c|}
\hline & Min & Max & Mean & Variance & $\begin{array}{c}\text { Standard } \\
\text { deviation }\end{array}$ & Skewness & Kurtosis \\
\hline Eurostoxx50 & -0.195 & 0.123 & -0.002 & 0.002304 & 0.048 & -0.896 & 1.882 \\
\hline OMX Riga & -0.273 & 0.334 & 0.01 & 0.004356 & 0.066 & 0.151 & 6.403 \\
\hline OMX Tallinn & -0.347 & 0.352 & 0.011 & 0.005041 & 0.071 & -0.237 & 5.872 \\
\hline OMX Vilnius & -0.374 & 0.333 & 0.008 & 0.004761 & 0.069 & -0.737 & 7.719 \\
\hline
\end{tabular}

Source: performed by the author.

\section{Analysis of the Wavelet Power Spectrum of Returns}

Table 1 presents the risk of investment as measured by the variance of returns. Table 1 reveals that the variance of the Baltic stock returns is approximately twice as high as the variance of the European stock returns. Our next focus was to investigate the variance at different time moments and at different frequencies (time periods). We converted frequency into time units (years), ranging from the highest frequency which corresponds to the period of 0.25 years to the lowest frequency corresponding to the period of 4 years. The minimal scale of 0.25 corresponds to 0.25 years or 3
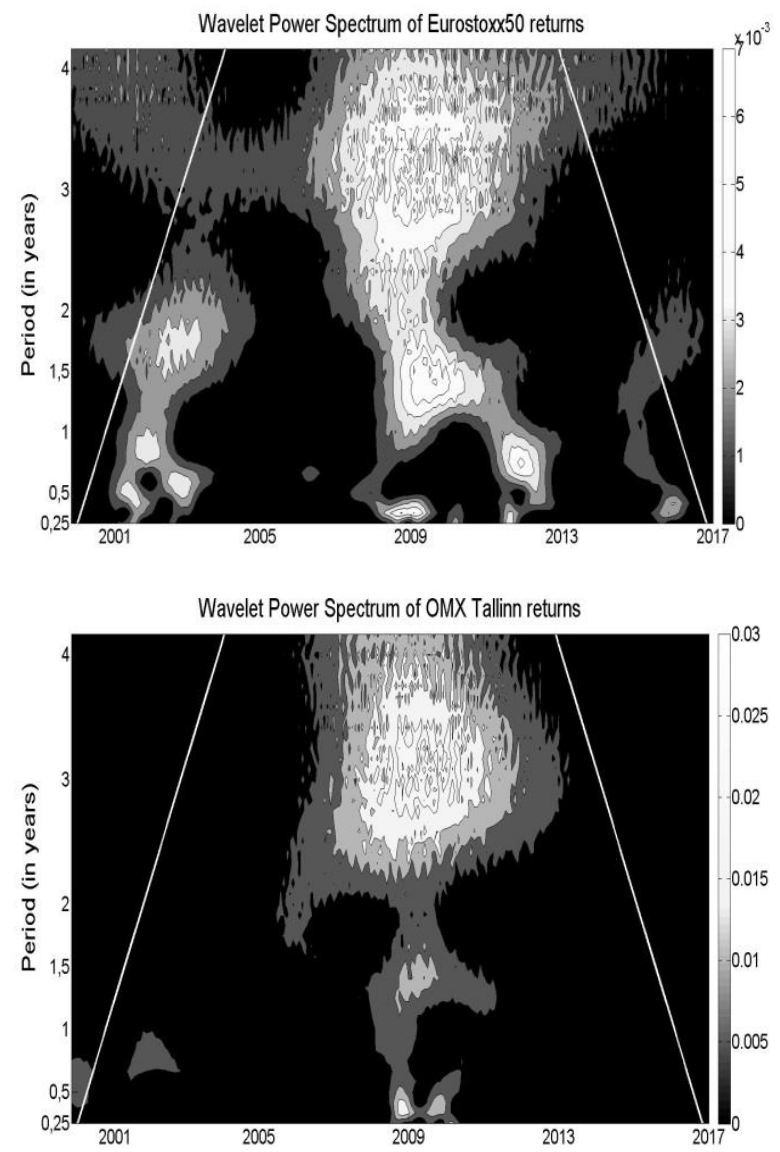

months, and the maximum scale corresponds to 4 years or 48 months. Figure 2 presents wavelet power spectrum for each market. The $\mathrm{x}$-axis refers to time and the $\mathrm{y}$-axis refers to the period or frequency.

Torrence and Webster (1999) noted that CWT, and accordingly WPS, suffers from the edge effect due to the fact that wavelets are not completely localised in time. Therefore, we include the cone of influence which is shown in white colour in the figures. Outside of the cone of influence, the results can be affected by the edge effect. The contour plot uses white colour for the high value of WPS and black for the low value of WPS.
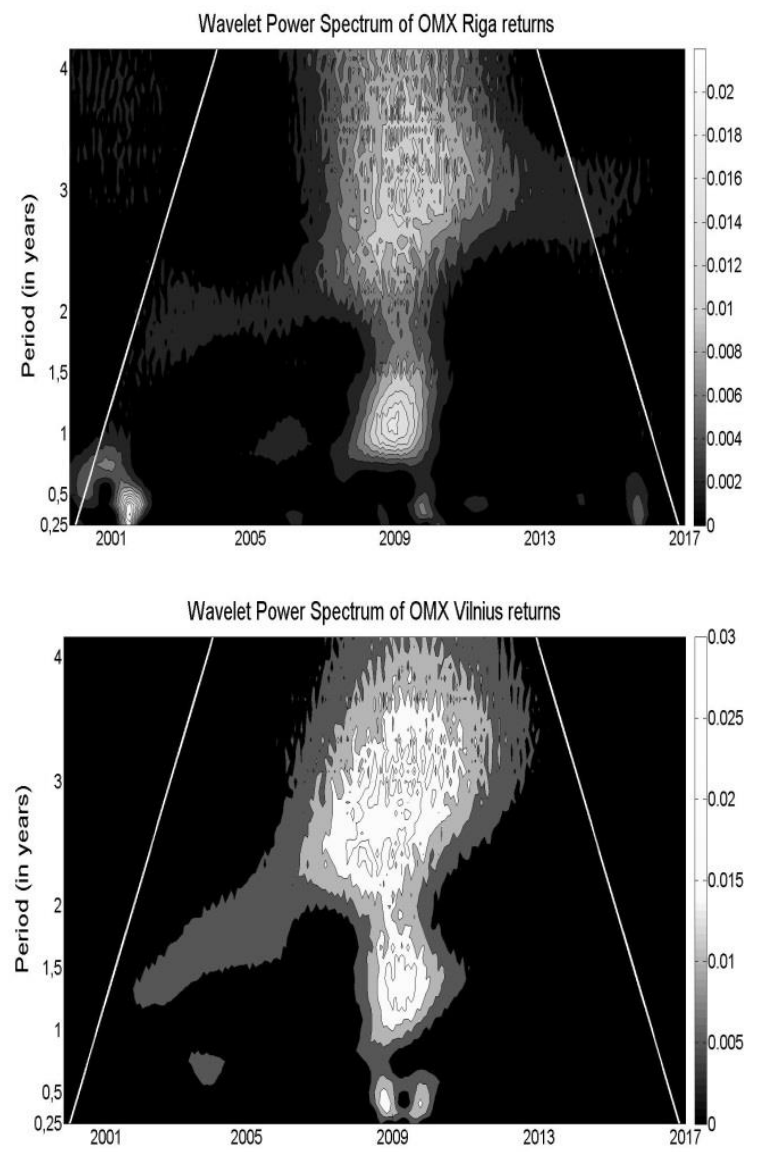

Figure 2. WPS for Eurostoxx50, OMX Tallinn, OMX Riga and OMX Vilnius indices. Source: performed by the author. 
Some findings can be made from analysis of WPS. First, as Figure 2 reveals, magnitude of WPS and consequently volatility of monthly returns is not uniform in frequency and time. In the time dimension, the highest volatility is observed in all the markets from 2007 to 2012 (bright colours). The above is related to the world financial crisis which started in the USA and then spread across the world later on. The period of the financial crisis in the USA started in December 2007 and lasted till June 2009, as defined by the National Bureau of Economic Research (NBER). The effect of the crisis was followed by the European sovereign debt crisis which was partially resolved by restructuring the Greece sovereign debt in the beginning of 2012. As we see from Figure 2, the mentioned circumstances had an impact on the European and the Baltic market risk as measured by WPS. The Eurozone stock market was affected by the Turkish crisis in 2001 (see Rua and Nunes (2012)). From Figure 2 we see that the crisis has increased WPS for the European market. We have not noticed a sizeable influence of the Turkish crisis on the Baltic markets, except for a small influence on Latvia.

In the frequency dimension, volatility is concentrated in the medium and long periods for all the markets. The impact of the crises is reflected in the scales from 0.75 to 3.5 years for all the markets under consideration. Noteworthy, the highest volatility is observed at the scale of around 3 years. Yet, Rua and Nunes (2012) found that the volatility of the returns of Morgan Stanley Capital International (MSCI) world index and MSCI index of the emerging markets was concentrated in the low scales (high frequencies) during the period of 1988-2008. The differences can be explained by the fact that the essential drop of the equity market, related to the Lehman Brothers collapse in September 2008, created a longlasting effect on the values of the indices (see Figure 1).

A more aggregate measure of volatility is the average of WPS across the time in each scale, which is denoted by $\mathrm{E}(\mathrm{s})$. Figure 3 presents $\mathrm{E}(\mathrm{s})$ for all the markets under consideration. We can see two local maximum values of the average of WPS for Eurostoxx50, Lithuania and Estonia. The first local maximum value is observed around the frequencies corresponding to 1.5 years and the second is found around 3 years. The maximum global value of $\mathrm{E}(\mathrm{s})$ is achieved at the frequencies of around 3 years (see Figure 3 ). For Latvia, the local maximum value which stands at 1.5 years for the other markets is shifted to 1 year and volatility of the average of WPS is observed for shorter periods. In Figure 2 we can see a brighter white colour for Latvia at the periods from 0.5 to 1.5 years. That can be explained by the fact that the crisis of 2008 in the Baltic countries started in Latvia, related to the bankruptcy of Parex bank, and was resolved with the help from IMF. Figure 2 shows a concentrated white colour for Latvia in 2008 at the scale of around 1 year. The average of WPS decreases at the frequencies corresponding to over 3 years for all the markets under investigation.

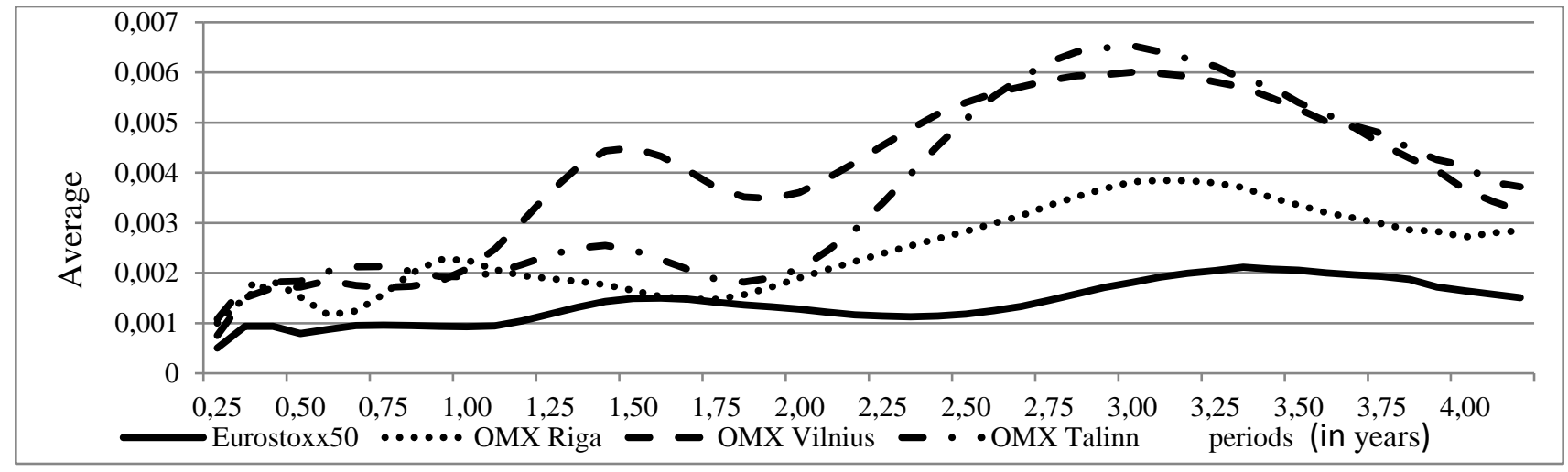

Figure 3. Average of wavelet power spectrum E(s) of Eurostoxx50, OMX Tallinn, OMX Riga and OMX Vilnius. Source: performed by the author.

Analysis of Wavelet Coherence of Returns

Pearson's Correlation Coefficients between Stock Market Returns

\begin{tabular}{|l|c|c|c|c|}
\hline & Eurostoxx50 & OMX Riga & OMX Tallinn & OMX Vilnius \\
\hline Eurostoxx50 & 1 & $0.169^{* *}$ & $0.213^{* *}$ & $0.237^{* * *}$ \\
\hline OMX Riga & & 1 & $0.433^{* *}$ & $0.445^{* *}$ \\
\hline OMX Tallinn & & & 1 & $0.724^{* * *}$ \\
\hline OMX Vilnius & ${ }^{* *} 5 \%$ significance level, ${ }^{* * *} 1 \%$ significance level \\
Source: performed by the author.
\end{tabular}

Co-movements between two time series can be measured by correlation of the series. Correlation coefficients are presented in Table 2.
Next, we go deeper into analysis of co-movements of the two time series in time-frequency domain. We measure coherence by $R^{2}(\tau, s)$, which varies depending on time $\tau$ and frequency as measured by s. Coherence between Eurostox 50 and indices of the Baltic countries is presented in Figure 4. 

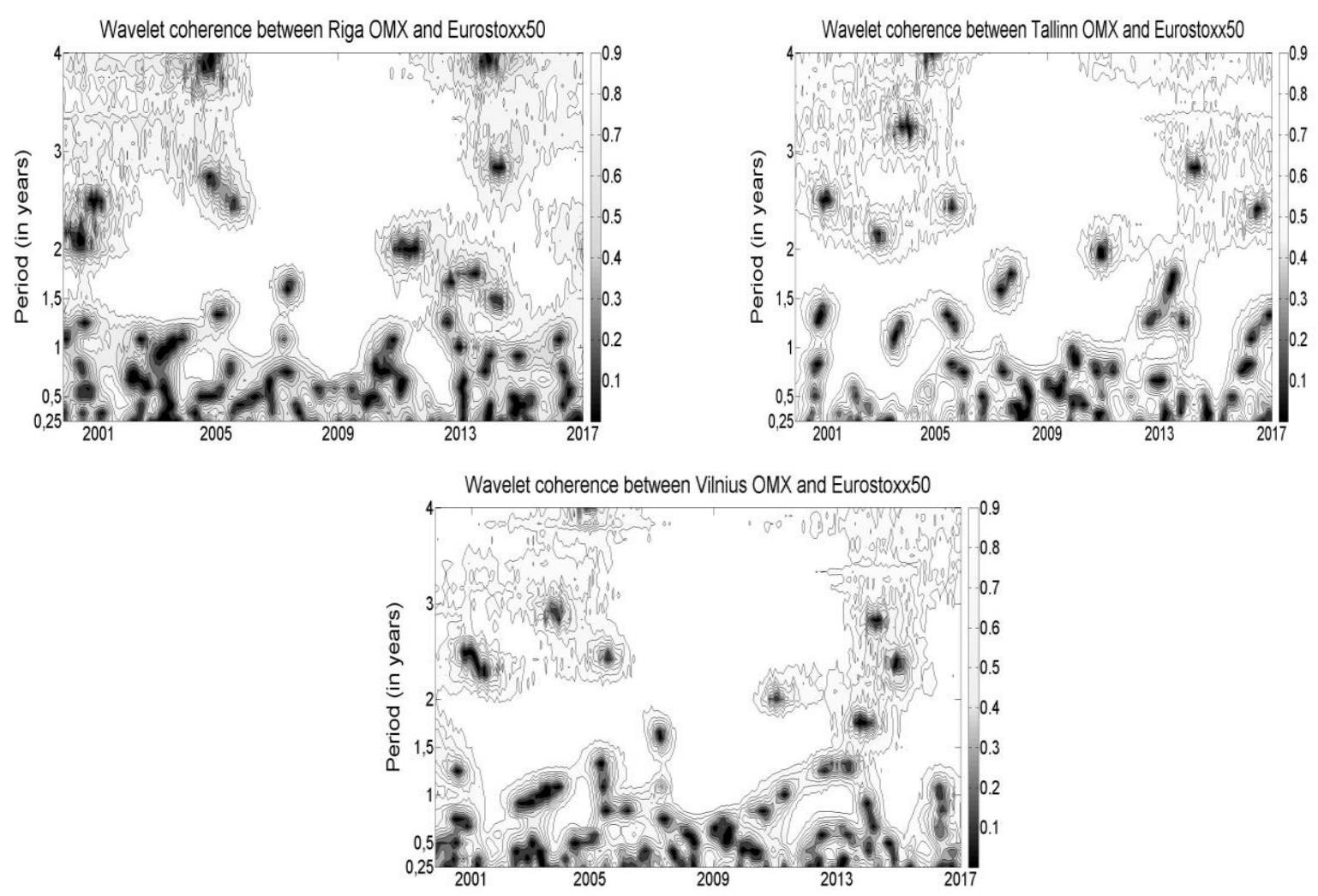

Figure 4. Coherence between Eurostoxx50 and of OMX Tallinn, OMX Riga and OMX Vilnius Source: performed by the author.

When looking at the time scales in Figure 4 we can find that coherence between the euro market and the markets of all the Baltic countries increased (white colour is dominant) from 2007 to 2013 for all the periods exceeding 1 year. The coherence decreased between the markets after the year of 2013. This was the time when the sovereign debt problem was resolved partially and tension decreased in all the markets.

Noteworthy, starting from 2001 (in May 2004 the Baltic countries accessed the EU) the coherence increased in the frequencies corresponding to around 1.5 years.
We see some increase of the coherence for Latvia in the middle of 2013 and for Lithuania in the middle of 2014, which can be treated as the time of the announcement of the European Commission concerning the introduction of the euro in these countries. We do not see any impact of the introduction of the euro in 2011 in Estonia. It can be explained by the fact that the coherence was still very high because of the crisis in 2010 .

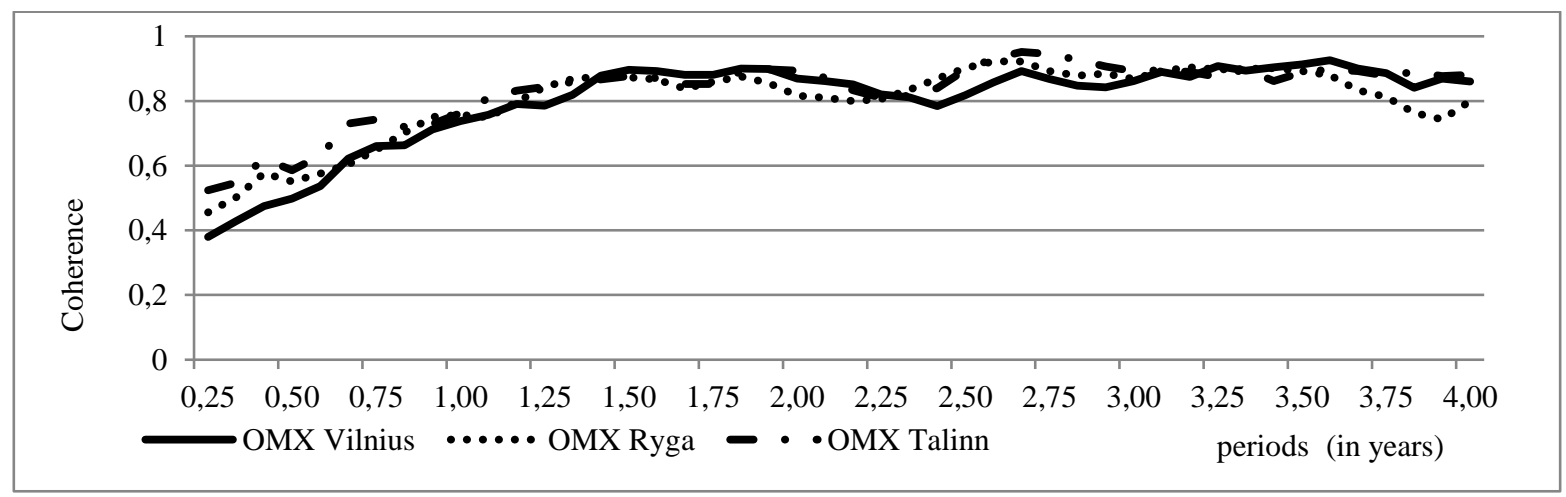

Figure 5. Average coherence $\mathrm{AC}(\mathrm{s})$ of Eurostoxx 50 and indices of the Baltic markets. Source: performed by the author.

The average of $R^{2}(\tau, s)$ is presented in Figure 5. We see that the average coherence is higher than 0.8 in longer periods (low frequencies), i.e. from 1.25 to 4 years, and lower in shorter periods. The above shows that comovements of the Baltic markets with the Eurozone market are very high for long periods. The average coherence between the European markets and the Baltic markets is small for the periods shorter than 0.5 years. Hence, comovements are high for long periods and low for short periods.

The economies of the Baltic countries are very open and closely related to the EU economies. It can be the reason why the Baltic equity market depends on the EU fundamentals and co-movements are high at low frequencies 
(long periods). The co-movements have increased as a result of the accession to the EU and during the time of the global financial crises. The weak co-movements at higher frequencies are related to low liquidity of the Baltic markets and the countries' specific issues.

\section{Conclusions}

Compared to the previous studies, a novelty of the paper is the use, for the first time, of wavelet analysis for investigation of the Baltic markets. The previous analyses of the Baltic markets were made by applying a classical econometrical approach. Wavelet analysis has a very important advantage. It allows decomposing of the time series of returns into time and frequency dimensions. The decomposition creates opportunities to compare different markets not only in time, but also in frequency. Our findings corroborate the findings from other authors that crisis periods have a great impact on interrelations of the global, the European and the Baltic markets. The results are consistent with the findings of other researchers, such as Nikkinen et al. (2012) who indicated that the Baltic markets were more integrated with the developed European stock markets during crisis periods. Our investigation goes deeper into co-movements. We discover that co-movements of the markets are high in the period from 2007 to 2013 for the investments exceeding 1.5 years.

We discover that volatility is focused in the medium and long periods (medium and low frequencies) from 0.75 to 3.5 years for all the markets under consideration. The absolute maximum of volatility is achieved at the period of 3 years and persists from the year 2007 to 2012. Another local maximum is recorded at the period of 1.5 years from the year 2008 to 2010 for all the markets except Latvia. For the Latvian market, the maximum at the period of 1.5 years is shifted to the left, i.e. to the period equal to 1 year. It is well known that Latvia is one of the first countries which have faced banking and sovereign debt problems. Hence, a hypothesis emerges that volatility at the period from 1 to 1.5 years is related to the sovereign debt problems in Europe and volatility at the high scales tallies with the global world crisis. We find some impact of accession to the EU and the introduction of the euro on co-movements between the Baltic equity markets and the European market. Starting from 2001 (in May 2004 the Baltic countries accessed the EU, whereas active negotiation started in 2001), comovement increased in the frequencies corresponding to the period of around 1.5 years. The impact of the euro introduction is moderate. Co-movements are slightly higher after the announcement of the euro introduction by the European Commission for Latvia and Lithuania. The impact of the introduction of the euro in Estonia is not observed. It can be explained by the fact that the European Commission announced about the introduction of the euro in the middle of 2010 and the coherence was still very high because of the crisis. The economies of the Baltic countries are very open and closely related to the EU economies. It can be the reason why the Baltic equity market depends on the EU fundamentals and co-movements are high at low frequencies (long periods).

The results of the paper are relevant for better understanding of the behavior of the Baltic stock markets, especially for investors. We have established that comovement of the Baltic markets with the European market is very high in low frequencies. Hence, our conclusion is that for the investor with the time horizon exceeding 1.5 years the diversification with the Baltic markets is not very efficient. The benefit of the diversification can be achieved for the investors with the time horizons of less than 1 year.

For the further research the current study could be linked to modern risk measurement techniques such as Value at Risk, Expected Shortfall, etc. As a result, the quantitative estimation of the risk for the given portfolio along with the relevant investment horizon could be obtained. For the future research the wavelet transformation could be used to investigate contagion of the markets by using higher frequencies with more frequent data. Furthermore, it should be beneficial to focus the future research on the analysis of co-movements of the Baltic markets with the Nordic and the Central European markets. Wavelet transformation could be useful to analyse inter-asset dependencies at different frequencies. The relationship between stock markets returns and macro-economic variables for various time horizons could be one of the guidelines for the policy makers.

\section{References}

Addison, P. S. (2017). The Illustrated Wavelet Transform Handbook: Introductory Theory and Applications in Science, Engineering, Medicine and Finance. CRC Press.

Alekneviciene, V., Alekneviciute, E., \& Rinkeviciene, R. (2012). Portfolio Size and Diversification Effect in Lithuanian Stock Exchange Market. Inzinerine Ekonomika-Engineering Economics, 23(4), 338-347. https://doi.org/10.575 5/j01.ee.23.4.2565

Alexakis, D. P., Kenourgios, D., \& Dimitriou, D. (2016). On emerging stock market contagion: the Baltic region. Research in International Business and Finance, 36, 312-321. https://doi.org/10.1016/j.ribaf.2015.09.035

Babalos, V., Balcilar, M., \& Loate, T. B. (2018). Did Baltic stock markets offer diversification benefits, Empirica, 36, 29-47. https://doi.org/10.1007/s10663-016-9344-4

Banulescu-Radu, D., Hurlin, C., Candelon, B., \& Laurent, S. (2016). Do we need high frequency data to forecast variance? Annals of Economics and Statistics, GENES 123, 135-174.

Barunik, J., \& Vacha, L. (2013). Contagion among Central and Eastern European stock markets during the financial crisis. Czech Journal of Economics and Finance, 63(5), 443-453. 
Bein, A. M. (2017). Time-varying Co-Movement And Volatility Transmission Between The Oil Price And Stock Markets In The Baltics And Four European Countries. Inzinerine Ekonomika-Engineering Economics 28(5), $482-493$. https://doi.org/10.5755/j01.ee.28.5.17383

Brooks, R., \& Del Negro, M. (2005). Country versus region effects in international stock returns. Journal of Portfolio Management, 67-72. https://doi.org/10.3905/jpm.2005.570152

Brooks, R., \& Del Negro, M. (2006). Firm-level evidence on international stock market comovement. Review of Finance, (10), 69-98. https://doi.org/10.1007/s10679-006-6979-1

Candelon, B., Piplack, J., \& Straetmans, S. (2008). On measuring synchronization of bulls and bears: The case of East Asia. Journal of Banking and Finance, (32), 1022-1035. https://doi.org/10.1016/j.jbankfin.2007.08.003

Chakrabarty, A., De, A. Gunasekaran, A., \& Dubey. R., (2015) Investment horizon heterogeneity and wavelet: Overview and further research directions, Physica A. Statistical Mechanics and its Applications, 429 (2015) 45-61. https://doi.org/10.1016/j.physa.2014.10.097

Dajcman, S. (2012). The dynamics of return comovement and spillovers between the Czech and European stock markets in the period 1997-2010. Czech Journal of Economics and Finance, 61(4), 368-390.

Deltuvaite, V. (2016). Investigation of Stock Markets Integration in the Baltic Countries. Economics and Business, (28), 3844. https://doi.org/10.1515/eb-2016-0006

Dewandaru, G., Masih, R.,. \& Masih, A., M. (2015) Why is no financial crisis a dress rehearsal for the next? Exploring contagious heterogeneities across major Asian stock markets, Physica A. Statistical Mechanics and its Applications, 419 241-259. https://doi.org/10.1016/j.physa.2014.10.046

Egert, B., \& Kocenda, E. (2010). Time_varying synchronization of European stock markets. Empirical Economics, (40), 393-407.

Forbes, K., \& Rigobon, R. (2002). No contagion, only interdependence: Measuring stock market comovements. Journal of Finance, (57), 2223-2261. https://doi.org/10.1111/0022-1082.00494

Gilmore, G. C., \& McManus, G. M. (2002). International portfolio diversification: US and Central European equity markets. Emerging Markets Review, (3), 69-83. https://doi.org/10.1016/S1566-0141(01)00031-0

Gallegati, M. (2008). Wavelet analysis of stock returns and aggregate economic activity. Computational Statistics \& Data Analysis, 52(6), 3061-3074. https://doi.org/10.1016/j.csda.2007.07.019

Gallegati, M., Ramsey, J., \& Semmler, W. (2014). Interest rate spreads and output: A time scale decomposition analysis using wavelets. Computational Statistics \& Data Analysis, 76(C), 283-290. https://doi.org/10.1016/j.csda. 2014.02.024

Grinsted, A., Moore, J., \& Jevrejeva, S. (2004). Application of the cross wavelet transform and wavelet coherence to geophysical time series. Nonlinear processes in geophysics, 11.5/6, 561-566.

King, M., \& Wadhwani, S. (1990). Transmission of volatility between stock markets. Review of Financial Studies, (3), 533. https://doi.org/10.1093/rfs/3.1.5

Kim, S., \& In, F. (2003). The relationship between financial variables and real economic activity: evidence from spectral and wavelet analyses. Studies in Nonlinear Dynamics \& Econometrics, (7), no. 4, article 4. https://doi.org/10.22 02/1558-3708.1183

Kim, S., \& In, F. (2005). The relationship between stock returns and inflation: new evidence from wavelet analysis. Journal of Empirical Finance, (12), 435-444. https://doi.org/10.1016/j.jempfin.2004.04.008

Kregzde, A., \& Murauskas, G. (2015). Analysis of Lithuanian Credit Default Swaps, Journal of Business Economics and Managemen.t 34(1), 144-155. https://doi.org/10.3846/16111699.2014.890130

Kuusk, A., Paas, T., \& Viikmaa, K. (2011). Financial contagion of the 2008 crisis: Is there any evidence of financial contagion from the US to the Baltic states. Eastern Journal of European Studies, 2(2), 61-76.

Lin, W.-L., Engle, R., \& Ito, T. (1994). Do bulls and bears move across borders? International transmission of stock returns and volatility. Review of Financial Studies, vol. 7, no. 3, 507-538. https://doi.org/10.1093/rfs/7.3.507

Ling, X., \& Dhesi, G. (2010). Volatility spillover and time varying conditional correlation between the European and US stock markets. Global Economy and Finance Journal, (3), 148-164.

Nekhili, R., Aslihan A. S., \& Gencay, R. (2002). Exploring exchange rate returns at different time horizons. Physica A, 313, 671-682. https://doi.org/10.1016/S0378-4371(02)00986-X

Nikkinen, J., Piljak, V., \& Aijo, J. (2012). Baltic stock markets and the financial crisis of 2008-2009. Research in International Business and Finance, (26), 398-409. https://doi.org/10.1016/j.ribaf.2012.03.003

Maneschiold, P. O. (2006). Integration between the Baltic and international stock markets. Emerging Markets Finance and Trade, 42(6), 25-45. https://doi.org/10.2753/REE1540-496X420602 
Syllignakis, M. N., \& Kouretas, G. P. (2011). Dynamic correlation analysis of financial contagion: Evidence from the Central and Eastern European markets. International Review of Economics and Finance, (20), 717-732. https://doi.org/10.1016/j.iref.2011.01.006

Pakko, M. (2004). A spectral analysis of the cross-country consumption correlation puzzle. Economics Letters, (84), 341347. https://doi.org/10.1016/j.econlet.2004.03.003

Polanco-Martinez, J. M., Fernandez-Macho, J., Neumann, M. B., \& Faria, S. H. (2018). A pre-crisis vs. crisis analysis of peripheral EU stock markets by means of wavelet transform and a nonlinear causality test. Physica A: Statistical Mechanics and its Applications 490, 1211-1227. https://doi.org/10.1016/j.physa.2017.08.065

Ramsey, J., \& Lampart, C. (1998). The decomposition of economics relationships by time scale using wavelets: expenditure and income. Studies in Nonlinear Dynamics and Econometrics, (3), 23-42. https://doi.org/10.2202/1558-3708.1039

Ramsey, J., \& Zhang, Z. (1996). The application of wave form dictionaries to stock market index data. In: Kratsov, Y. and Kadtke, J., Springer (eds) Predictability of complex dynamical systems. https://doi.org/10.1007/978-3-642-80254$6 \_11$

Ramsey, J., \& Zhang, Z. (1997). The analysis of foreign exchange data using waveform dictionaries. Journal of Empirical Finance, (4), 341-372. https://doi.org/10.1016/S0927-5398(96)00013-8

Rua, A., \& Nunes, L.C. (2009). International comovement of stock market returns: A wavelet analysis. Journal of Empirical Finance, (16), 632-639. https://doi.org/10.1016/j.jempfin.2009.02.002

Rua, A. (2012). Money growth and inflation in the euro area: a time-frequency view. Oxford Bulletin of Economics and Statistics, (74), 875-885. https://doi.org/10.1111/j.1468-0084.2011.00680.x

Rua, A., \& Nunes, L. C. (2012). A wavelet-based assessment of market risk: The emerging markets case. Quarterly Review of Economics and Finance, 52, 84-92. https://doi.org/10.1016/j.qref.2011.12.001

Tiwari, A., K., Cunado, J., Gupta, R., \& Wohar, M. (2017).Are stock returns and inflation hedge for the UK? Evidence from a wavelet analysis using over three centuries of data. University of Pretoria Working papers, 2017-35.

Torrence, C., \& Compo, G. (1998). A practical guide to wavelet analysis. Bulletin of the American Meteorological Society, (79), 61-78. https://doi.org/10.1175/1520-0477(1998)079<0061:APGTWA>2.0.CO;2

The article has been reviewed.

Received in October, 2017; accepted in December, 2018. 